\title{
The Neonatal Behavioral Observation System: A tool to enhance the transition to motherhood
}

\begin{abstract}
Background: Shorter hospitalisation after childbirth raises new challenges in the transition to parenthood.

Aim. This paper reports a study designed to identify first-time mothers' experience with The Neonatal Behavioral Observation System (NBO) as a guiding model.

Method: A phenomenological qualitative study sampling four first-time mothers who received guidance from the NBO-specialist nurse two days after delivery. Interviews were conducted using a semi-structured interview guide.
\end{abstract}

Findings: Analysis revealed three themes describing the mothers positive experience of the guidance model: a) a new understanding of the baby's communication abilities, b) an increased feeling of competence and confidence in dealing with challenges in caretaking issues, and c) being treated as individuals encouraged to make their own decisions.

Conclusion: The NBO system can be used in clinical practice to enhance the transition to motherhood and family life and to provide support during the post-partum period. More research on the impact of NBO that includes fathers as well as different groups of at-risk parents is recommended.

Key words: First-time mothers, Neonatal Behavioral Observation, qualitative method, transition to motherhood. 


\section{INTRODUCTION}

The trend toward shorter hospitalisations after childbirth raises new challenges in the transition to parenthood $(1,2)$. While mothers in Norway previously stayed in the hospital for up to 1 week post-partum, they are now typically discharged after 3 days or less (3). This seems to be the norm in most western countries $(4,5)$. The process of becoming a parent involves developing both a relationship with the baby and competence and confidence in caregiving tasks (6). A number of studies from the past decade have addressed the challenges many parents experience in the transition to parenthood $(4,7-11)$. Few qualitative studies have addressed infant personality and temperament or how to encourage bonding and interaction with the child. However, Sanders and Buchner address these issues in their study of the Neonatal Behavioral Observation System (NBO) (12). The study examines the use of the NBO as a nursing intervention to enhance engagement in first-time mothers. The authors found that the NBO was effective in enhancing mother-infant engagement and the mothers rated the NBO high as a means of increasing their knowledge of their infants.

\section{BACKGROUND}

In the last three decades, a new understanding of the infant has emerged through insights from research. Stern identified the establishment of a positive mother-infant relationship as a way to develop mutual love between mother and child (13). Brazelton recognised that infants have the ability to communicate and express themselves even in the early postpartum period, and they do so in ways that elicit parental responses. He expressed concern about at-risk parents and their parental role and the cultural implications of the parental role (14). Together with his colleagues, he created the NBO system as a flexible clinical intervention tool to support parents during their transition to parenthood and to promote positive parent-infant relationships (15). The infant's capacities are described through eighteen neurobehavioral 
observations (Table 1). Health workers such as nurses, midwives, district nurses and psychologists certified through a NBO training programme can carry out the method. By sensitising parents to their child's competencies, strengths and personality, the NBO teaches parents to respond to their baby's needs more appropriately. When the parents are positively

nurtured, they feel encouraged and competent in their parenting role (15). The child's first year of interaction with the mother and the mother's sensitivity, i.e., how quickly and appropriately she reacts to the child's signals, seem to be of special importance. Equally important is the caregiver's ability to regulate the child's different stages (e.g., the sleeping, awake and crying stages) and to take the initiative in interactions with the child (13).

\section{METHODS}

\section{Design}

A qualitative approach based on a phenomenological understanding and perspective was used to collect in-depth information about the mothers' experience with the NBO intervention model. The aim of the study was to create an understanding of the mothers experience based on each participant's description. This may contribute to an in-depth understanding of the NBO's impact on mother-infant relationship seen from the mothers' perspective.

\section{Sample}

A purposeful sampling of first-time mothers with healthy babies was recruited. The inclusion criteria were Norwegian-speaking first-time mothers who had delivered a healthy child and were admitted to the maternity ward at a Norwegian university hospital. The hospital delivers 2.500 babies annually. The exclusion criteria were women who had delivered via caesarean section, as caesarean delivery may interfere with mother-baby interaction. The mothers were invited consecutively by the NBO nurse to participate in the study on the $2^{\text {nd }}$ day postpartum. 
The introduction to the study included written information and a consent sheet. After the mothers were enrolled in the study, a qualified NBO nurse guided them through one NBO intervention. This lasted approximately 45 minutes. The PI conducted the following interviews. She did not perform the interventions. The father was present in 3 of the 4 cases. The fathers were not interviewed, as the aim of this study was to investigate the mothers' experience.

\section{Procedure}

Data were collected two weeks after discharge applying in-depth, semi-structured, homebased interview. Home-based interviews were chosen because the mother and child had been discharged from hospital at that point, and it was important to make participating convenient for the mothers. We believed that after two weeks, the mothers would have begun adjusting to their new role.

An interview guide ensured the inclusion of key questions. The principle investigator (PI) was a RN, specialized in neonatology and qualified to conduct NBO interventions. This contributed to determining the focus of the interviews. The interview began with open-ended questions asking the mother to describe how she experienced the meeting with the NBO nurse. From there, the mother was asked to describe how she experienced parts and details of the intervention and what implications and relevance it might have for her and her child. It was important to allow the participants to take their time describing their experience and to talk freely without interruption. This gave them the opportunity to raise issues that were not specifically addressed in the interview guide.

Each interview lasted approximately 45 minutes and was audio-recorded. The father was at home during the interview in one case, but he left the room when the interview began. The baby was present in 3 of the 4 cases. The interviews were transcribed verbatim by the PI. All 
4 interviews were replayed several times and compared with the typed transcripts for accuracy prior to analysis. Sighs, laughs, changes of voice/tone and other non-verbal expressions were noted on the transcripts (16).

\section{Ethical considerations}

The Regional Committee for Medical Research Ethics and the head of the hospital clinic reviewed and approved the study. To avoid putting the mothers in a loyalty conflict and enable them to answer sincerely, two different persons conducted the NBO intervention and the interviews. The interviewer was aware of the issue of interviewing mothers in their private homes.

\section{ANALYSIS}

The data analysis is an on-going process that began with the interviews. A phenomenological approach was applied. The data were analysed using Giorgi's method for content analysis approach $(17,18)$ adjusted according to the method of Malterud (19). The following four steps were applied:

1. Gaining a sense of the material as a whole by repeatedly listening to the audiotapes and reading the entire transcript of each interview.

2. Identifying meaning units by breaking up the text, focusing on the phenomena being studied and the participants' experience.

3. Extracting contents from each meaning unit and transforming everyday language into professional terminology to create a general structure. 
4. Synthesising the transformed meaning units. The meaning was reproduced in a simple way, and the resulting text described the participants' experience.

The participants' experience with NBO affected their reflection on the phenomena. This reflection was influenced by their individual experiences and life influences (18). Malterud indicates that decontextualisation allows parts of what is being researched to be separated out and investigated closely (20). The analysis process led to the identification of core themes and descriptions. The PI's prior understanding of the phenomena, arising from her experience as a nurse who supported and guided families in their transition to parenthood, was presumed likely to affect the data analysis. Therefore, the findings were discussed between the authors.

\section{RESULTS}

The participating mothers were all white and in a relationship with the baby's father, and they lived in a medium-sized Norwegian town. They ranged from 22 and 30 years old and all had a minimum of a high-school education. Two were students, and two were employed full-time prior to giving birth.

Through the analysis process, three main themes emerged to describe the mothers' experience of having participated in the NBO intervention:

- A new understanding of the baby

- A feeling of greater competence and confidence

- Being treated as an individual 


\section{Theme one: A new understanding of the baby's communication abilities}

All participants stated that they were surprised by their baby's ability to interact with them by looking at them, focusing his/her eyes, and following them with his/her eyes and head. The mothers had not realised the baby's great ability to communicate at such an early stage:

\footnotetext{
"You may think that they only eat and sleep, but they don't."

"After nine months, he recognised my voice. It was so nice."
}

This new understanding of the baby's communication abilities seems to have given the mothers a new agenda when interacting and communicating with their infants. The mothers expressed a wish to interact with the baby and play or "talk" to him/her rather than leave the baby on its own. These interactions made the mothers happy:

\footnotetext{
"Even if you have been feeling exhausted the whole day, you just, it is as if you get such a boost of energy, you just become very happy."

"I have focused more now on when he is awake that I want to do something together with him, should I say, find something to do... I don't want him just to lie there..."
}

The NBO showed the mothers how to facilitate a positive mother-baby interaction based on how the baby presented him- or herself. This helped the mothers identify, for example, when the baby showed signs of exhaustion. In this way, interactions with the baby can be adjusted to suit the baby's capacity and ability at a given moment.

\footnotetext{
"He sneezes when he has had enough in a way... he starts to sneeze and turn his head away, too. I don't think I would have thought this had anything to do with him being tired, the sneezing. I would have thought, 'Oh dear, poor thing, have you got a cold?'”
} 
The ability to identify the baby's signs also affected how the participants comforted and supported their baby when the baby seemed disorganised and/or unhappy. When observing a change in skin colour, the mothers were able to relate it to the baby being disorganised. They could then respond by swaddling the baby in a blanket to support his/her sleep or by supporting the baby's head and body while changing a diaper. Knowing when to support the baby and how to regulate the interaction is important and gave the participants confidence in their ability to care for the baby.

The fathers' presence (in 3 out of 4 cases) during the NBO session seems to have been important for the families. Three of the four mothers mentioned that the father's interaction and communication with the baby was beneficial to her and the family. The father played an active role in caring for the baby:

\footnotetext{
"I feel, I can see that he (the partner) is doing what she (the NBO nurse) showed us, he (the partner) has learned something new."
}

"If he (the baby) starts to cry, he (the partner) might as well pick him up and soothe him. That is also so nice, that he can comfort him so well."

"He (the partner) is very calm and confident. Maybe that is why he (the baby) is a calm baby."

The fathers acquired a new understanding of the baby's capabilities and enjoyed talking to and playing with the baby. They also enjoyed "showing off" the baby's skills to friends and family. 


\section{Theme two: Feeling an increase in competency and confidence}

The transition to motherhood requires adjusting to a new role. In the perspective of a major life change, the participants expressed the challenges in different ways:

\footnotetext{
"It is a great change in life. Even if you have wished for it to happen, it requires a big adjustment."

"Someone so dependent on me... it's a bit frightening, you can't imagine."
}

Sleep deprivation, lack of appetite, spending less time with friends and family and challenges in the relationship with the partner were also described.

Two of the mothers reported that they felt confidence in their ability to understand their baby's needs from the start. They did not think the NBO made a major difference. Still, the NBO gave them new knowledge about the baby's reaction to different caregiving situations. One participant felt that the NBO gave her the support and security she needed to rebuild her confidence. After returning home, she could make her own decisions based on her new knowledge. Another mother sometimes experienced her child as difficult and found that soothing him during periods of crying was especially challenging:

"I felt that he (the baby) didn’t really like me."

The NBO had changed her perception of the situation. She now felt more confident and able to soothe and handle the baby, and she felt that the baby wanted her to comfort him. She could now identify his cry, whether he wanted to eat or whether he was just tired and needed to sleep. Both she and her husband practiced their new knowledge through different care giving tasks. Through this, they experienced increased happiness in caring for the baby. 
“... Especially when he has been crying a lot and how I can soothe him, create a balance in his body and try to take things easy and try out things instead of panicking.”

The participants named communication and the techniques for supporting, soothing and calming the baby as the important aspects of the NBO intervention. They reported that their babies seemed comforted and relaxed.

All of the participants mentioned parenting challenges in terms of such baby behaviours as sleeping, crying and feeding. The NBO intervention and learning how to deal with these issues seemed to increase the mothers' ability to cope. The fact that the mothers felt calmer was reflected in their babies:

\footnotetext{
"When you see that things work out, it calms you down... it has been of great importance because it has calmed me down a lot, and I can see it in him (the baby) that I am more calm and that we have learnt through what she (the NBO nurse) told us.”
}

\section{Theme three: Being treated as an individual}

During the NBO session, the mothers had an opportunity to speak freely about their concerns:

"We talked openly, not so much according to a plan or agenda, about all the little things I said and wondered about... She (the NBO nurse) could give a few answers and help me along."

All of the participants were positive about the meeting and emphasised that it changed the way they interacted with their child by teaching them new things about the baby. They thought they were lucky to have been chosen as participants and said that participating in the NBO left them with a "good feeling". They felt they were "helped along" in their new role. The support they were given and the reassurance that they were able to handle the situation gave them confidence. This was not always the case during hospitalisation. 
One of the participants said that the hospital staff seemed to provide information based on rules and routines rather than on the needs of each individual. As an example, she mentioned an episode where she was given a "reprimand" for having given her baby a pacifier. She was told that this could interfere with breastfeeding. Through the NBO, she had a different experience:

\footnotetext{
"She (the NBO nurse) acted as someone in between who says, 'I can see that he (the baby) has a great need for sucking and I understand very well your desire to give him a pacifier, I really can see that."”
}

Another participant emphasised the diverging information given by the hospital staff. The nurses often gave different answers to the same question, and the advice seemed to be based on general routines and opinions. Through the NBO, the mothers experienced being treated as individuals who had the best knowledge of their child. They were encouraged to make their own decisions based on how they experienced their child and according to each situation.

\section{DISCUSSION}

Four first-time mothers with healthy babies were interviewed about their experience of receiving guidance from the NBO nurse the second day postpartum. They described the challenges they faced in the transition to motherhood and said that the NBO had helped them overcome these challenges. The mothers also described an increased attention toward and interest in their child and learning new maternal skills. They valued the confidence they held in the NBO nurse and the way she treated them as individuals. 
The infant's experience is a central part of the NBO, as is fostering a more inclusive, personal and relational approach to examining and caring for the infant and its family (15). The informants of this study underline this important issue by describing how they valued the practitioner's sensitivity to their needs and focus on their baby.

Stern emphasise the adult's role as the self-regulating other person in a child's life. He calls the caretaker's ability to regulate the baby's different stages "affect regulation" (21). The participants reported that trying to regulate these stages, especially crying, could cause distress and uncertainty. Christie (8) and Wilkins (31) have addressed similar challenges.

Our findings indicate that guidance from professionals has a positive impact on the transition to motherhood. Both Sanders \& Buchner, Ravn and Leahy-Warren support this finding, although Leahy-Warren reports that half of her informants relied on family or friends for information about these issues $(4,12,22)$.The NBO facilitates information and guidance by focusing on the baby's abilities within the context of the caretaker and family. In this way, it can contribute to reducing parental distress. Our study seems to indicate that the NBO had this influence. One could argue that the same response might occur with 30 to 45 minutes positive and nurturing attention towards mother and baby from a professional without conducting the NBO. Still, the NBO assures a number of items to be included.

Nelson underlines that among her participants, it was when the baby responded to his/her mother's communication attempts that the mother experienced herself as a mother (10). Sanders and Buckner support this finding. Participants in their study rated the NBO highly as a tool for learning how to respond to and interact with the baby and to increase engagement (12). According to Carolan, most mothers have succeeded in the transition to motherhood by the time the baby is 4 to 6 months old (7). Other researchers have found that this transition happens at about 3 months (23). Engagement is necessary to establish a positive mother-child 
relationship early in the child's life. Our study's findings indicate that the NBO can help this transition in taking place.

Along with knowledge of the baby's capacity and early skills comes the opportunity for parents to regulate their interactions with their child in an appropriate way. One participant's statement that "I have been made aware of the importance of giving him a little time..." reflects the mother's understanding of how to facilitate optimal interaction with her child.

Mothers' ability to regulate this interaction and respond to their infant's temperament is of great importance during the baby's first year $(24,25)$. It also seems to have an effect on the child's later development $(22,24-28)$. Other quotes, such as "I want to do something together with him" and "Here I am, and there you are", indicate an increase in the mothers' sensitivity towards the child and their pleasure with their interactions. Creating interest and engagement for the infant at an early stage also seems to be relevant in light of the current increased focus on social media and the Internet. Being constantly online might be a factor that draws parents' attention away from the child.

The participants in this study identified that a feeling of confidence, learning about the baby and being able to attend to the baby's needs, and the pleasure of interacting with the baby at an early stage played a significant role in the transition to motherhood. The NBO also seemed to engage the fathers; therefore, it may have an impact on how the father relates to his child during the early stages of fatherhood. The NBO addresses individual families. The participants of this study valued this. Most parents will explore their infants, find solutions and manage interactions with their baby regardless of whether they are familiar with the NBO. However, the NBO seemed to help revealing the baby's abilities to the parents in the early postpartum period, and both the mothers and the fathers were surprised at what they discovered. 
According to Bandura, parental self-efficacy (PSE) corresponds to a) the parents' personal beliefs about how to master a challenge; b) what a parent can do with his/her capabilities under a set of conditions; and c) a set of organised actions taken in response to a set of tasks under difficult circumstances (29). Bandura propose that PSE is influenced by the parent's psychological state and mood and the perceived difficulty of a task. Challenges related to the infant's health status, maturity and sex might also have an influence $(29,30)$. A baby with demanding and challenging characteristics will thus make the transition to parenthood more difficult. The participant in this study who stated "I take things as they come..." and "I feel very calm and confident" is, according to Bandura`s theory, more likely to master her challenges than two of the other participants, who stated “... one felt as if one wasn't a good mother" and "I felt he (the baby) didn't really like me". Such statements may indicate that the mothers experienced challenges in caring for the baby. Difficulties responding to the baby's cry and soothing the baby are known to cause parental distress $(10,31)$. When she has learned how to deal with these issues, the mother can use new techniques to support the child. If she succeeds, she is likely to experience a feeling of increased coping. Our findings reflect this when the mother who felt she was not a good mother says, "I am no longer afraid of doing the wrong thing”. Bandura argues that high PSE encourages parents to try more/new things and motivates their actions (29). Wilkins found that "doing it right" emerged as the core category in her study (31).

The fathers in this study seemed to develop an increased consciousness of their infant. Based on this and on other studies that address the fathers' role, one could argue the importance of the father being present during the NBO intervention and that the NBO contributes to an increased paternal SE $(30,32,33)$. Although mothers seem to achieve confidence in most caregiving tasks shortly after their discharge from the hospital, some require increased guidance $(5,31)$. 
The majority of parents adjust to parenthood without interventions. Still, the NBO can be a relevant tool for supporting vulnerable groups of parents, especially in light of the trend toward increasingly shorter hospital stays. A number of studies in the last decade addressed the importance of parental support (3-6, 8, 10, 26, 30, 31, 34-36).

\section{Transferability, reliability and validity}

There are certain limitations in this study, as it included only four white mothers who were in a relationship with their baby's father and who had a minimum of 12 years of education. All the mothers were Norwegian speaking. Thus, the findings cannot uncritically be transferred to other groups of mothers, including vulnerable groups. However, the results could suggest that other populations of mothers would benefit from the NBO intervention. We argue that, taking into consideration the study's limitations, our findings could indicate the need for a study on the use of the NBO intervention in vulnerable groups.

We considered it relevant that two different persons conducted the interventions and the interviews. This ensured that the mothers could speak freely about their experience with the NBO intervention. The PI's background as a neonatal nurse with clinical experience with using the NBO may have affected the interpretation of the data. Therefore, one must take into consideration the PI's prior understanding. Malterud refers to this as the reflectivity process (20). The data analysis and findings were discussed between the authors. In a qualitative study, different researchers will interpret data in ways that are different, depending on each researcher's perspective, but that are equally valid $(16,20)$. The reflexivity process helped the researcher reduce potential bias. This, together with demonstrating the analysing process ensures the validity of the study. 


\section{CONCLUSIONS AND NURSING IMPLICATIONS}

The findings in this study indicate the value of facilitating a good infant-mother (and father) relationship. Increasing parental SE may provide the basis for a better parent-infant interaction. This may be of significance and can be especially relevant in strengthening the abilities of first-time parents and parents at risk. We recommend further research because the relatively homogeneous sample of informants in this study cannot provide a complete picture of the NBO's impact in practice. We are aware that four informants is a small number. Still, their perspective gives us an understanding of their experience. We suggest research that includes different groups of at-risk parents as well as fathers' experiences $(11,32,37)$. The Neonatal Behavioral Observation can be a tool for use in clinical practice to enhance the transition to motherhood for first time mothers. The NBO is effective, easy to learn and can be administered by health care workers from different professions in the family's home or in hospital.

Table 1. NBO observational items

\begin{tabular}{|l|l|}
\hline 1 & Habituation to light \\
\hline 2 & Habituation to sound \\
\hline 3 & Muscle tone, arms and legs \\
\hline 4 & Rooting \\
\hline 5 & Sucking \\
\hline 6 & Hand grasp \\
\hline 7 & Shoulder and neck tone (pull to sit) \\
\hline 8 & Crawling response \\
\hline 9 & Response to face and voice \\
\hline 10 & Visual response (to face) \\
\hline 11 & Orientation to voice \\
\hline 12 & Orientation to sound (rattle) \\
\hline 13 & Visual tracking (red ball) \\
\hline 14 & Crying \\
\hline 15 & Soothability \\
\hline 16 & State regulation \\
\hline 17 & Response to stress: colour changes, tremor, startles \\
\hline 18 & Activity level \\
\hline
\end{tabular}


Nina Bøhle Cheetham, RN, MSc, Assistant Professor, Institute of Health and Care Sciences, UiT, The Arctic University of Norway, 9037 Troms $\varnothing$, nina.cheetham@uit.no

Tove Aminda Hanssen, RN, PhD, Postdoctoral research fellow,

Division of Cardiothoracic and Respiratory Medicine, University Hospital North-Norway, 9038 Troms $\varnothing$, tove.aminda.hanssen@unn.no

\section{References:}

1. Fink AM. Early hospital discharge in maternal and newborn care. Journal of Obstetric, Gynecologic, \& Neonatal Nursing. 2011;40(2):149-56.

2. Madden JM, Soumerai SB, Lieu TA, Mandl KD, Zhang F, Ross-Degnan D. Length-ofstay policies and ascertainment of postdischarge problems in newborns. Pediatrics. 2004;113(1):42-9.

3. Helsetilsynet. Korleis tek fødeinstitusjonane og kommunen vare på behova til barselkvinna og det nyfødde barnet i barseltida? Oslo: Statens helsetilsyn, 2011.

4. Warren L. First time mothers: social support and confidence in infant care. Journal of Advanced Nursing. 2005;50(5):479-88.

5. Kapp M. Mothers Perception of Confidence with Self-Care and Infant Care. The Journal of Perinatal Education. 1998;7(4):17-25.

6. Mercer R. Becoming a mother versus maternal role attainment. Journal of Nursing Scholarship 2004.

7. Carolan M. Doing It Properly: The Experience of First Mothering Over 35 Years. Health Care for Women International. 2005;26(9):764-87.

8. Christie J, Poulton BC, Bunting BP. An integrated mid range theory of postpartum family development: a guide for research and practice. Journal of Advanced Nursing. 2008;61(1):38-50.

9. Harwood K, McLean N, Durkin K. First-time mothers' expectations of parenthood: What happens when optimistic expectations are not matched by later experiences? Developmental psychology. 2007;43(1):1-12.

10. Nelson AM. Transition to motherhood. Journal of Obstetric, Gynecologic, \& Neonatal Nursing. 2003;32(4):465-77.

11. Olafsen KS, Ronning JA, Dahl LB, Ulvund SE, Handegard BH, Kaaresen PI. Infant responsiveness and maternal confidence in the neonatal period. Scand J Psychol. 2007 Dec;48(6):499-509. PubMed PMID: 18028072.

12. Sanders LW, Buckner EB. The Newborn Behavioral Observations System as a nursing intervention to enhance engagement in first-time mothers: Feasibility and desirability. Pediatric nursing. 2006;32(5):455-9.

13. Stern DN. The motherhood constellation: a unified view of parent-infant psychotherapy. New York: BasicBooks; 1995. VIII, 229 s. p.

14. Brazelton TB, Nugent JK. Neonatal behavioral assessment scale. London: Mac Keith Press; 1995. IX, 150 s. p. 
15. Nugent JK, Constance H. Keefer, Susan Minear, Lise C. Johnson, Yvette Blanchard. Understanding Newborn Behaviour Early Relationships. Baltimore-London-Sydney: Paul Brookes Publishing; 2007. 255 p.

16. Polit DF, Beck CT. Nursing research: generating and assessing evidence for nursing practice. Philadelphia, Pa.: Wolters Kluwer/Lippincott Williams \& Wilkins; 2008. XVIII, 796 s. p.

17. Giorgi A. Phenomenology and psychological research: essays. Pittsburgh, Pa.: Duquesne University Press; 1985. X, 216 s. p.

18. Giorgi A. The Descriptive Phenomenological Method in Psychologi. Pittsburgh: Duquesne University Press; 2009.

19. Malterud K. Kvalitative metoder i medisinsk forskning. 1 ed. Oslo: TanoAschehoug; 1996. 216 p.

20. Malterud K. Qualitative research: standards, challenges, and guidelines. The Lancet. 2001;358(9280):483-8.

21. Stern DN. Spædbarnets interpersonelle verden: et psykoanalytisk og udviklingspsykologisk perspektiv. København: Hans Reitzels forlag; 2000. 369 s p.

22. Ravn IH, Smith L, Lindemann R, Smeby NA, Kyno NM, Bunch EH, et al. Effect of early intervention on social interaction between mothers and preterm infants at 12 months of age: A randomized controlled trial. Infant Behavior and Development. 2011;34(2):215-25.

23. Miller T. Shifting perceptions of expert knowledge: Transition to motherhood. Human Fertility. 2003;6(3):142-6.

24. Røed Hansen B. Affektive Dialoger. Fra regulering til mentalisering. In: Slinning K, Hansen MB, Moe V, Smith E, editors. Håndbok i sped- og småbarns psykiske helse. Oslo: Gyldendal akademisk; 2010. p. 116-33.

25. Smith L, Ulvund SE. Spedbarnsalderen. Oslo: Universitetsforlaget; 1999. 576 s. p.

26. Assel MA, Landry S, Swank P, Steelman L, Miller Loncar C, Smith K. How do mothers childrearing histories, stress and parenting affect children's behavioural outcomes? Child: Care, health and development. 2002;28(5):359-68.

27. Mantymaa M, Puura K, Luoma I, Salmelin R, Davis H, Tsiantis J, et al. Infantmother interaction as a predictor of child's chronic health problems. Child: Care, health and development. 2003;29(3):181-91.

28. Nordhov M, Rønning J, Dahl LB, Ulvund S, Tunby J, Kaaresen P. Early Intervention Improves Cognitive Outcomes for Preterm Infants. Pediatrics. 2010;126(5):1088-94. Epub 10 oct. 2010.

29. Bandura A. Self-efficacy: the exercise of control. New York: Freeman; 1997. IX, 604 s. p.

30. Salonen AH, Kaunonen M, Åstedt-Kurki P, Jarvenpaa AL, Isoaho H, Tarkka MT. Parenting self-efficacy after childbirth. Journal of Advanced Nursing. 2009;65(11):232436.

31. Wilkins C. A qualitative study exploring the support needs of first-time mothers on their journey towards intuitive parenting. Midwifery. 2006;22(2):169-80.

32. Condon J. What about dad? Psychosocial and mental health issues for new fathers. Australian family physician. 2006;35(9):690-92.

33. Schumacher M, Zubaran C, White G. Bringing birth-related paternal depression to the fore. Women and birth. 2008;21(2):65-70.

34. Britton JR, Britton HL, Beebe SA. Early discharge of the term newborn: a continued dilemma. Pediatrics. 1994;94(3):291-5. 
35. Mercer RT, Walker LO. A review of nursing interventions to foster becoming a mother. Journal of Obstetric, Gynecologic, \& Neonatal Nursing. 2006;35(5):568-82.

36. SmithBattle L. Learning the baby: An interpretive study of teen mothers. Journal of Pediatric Nursing. 2007;22(4):261-71.

37. Leahy-Warren P, McCarthy G, Corcoran P. First-time mothers: social support, maternal parental self-efficacy and postnatal depression. Journal of Clinical Nursing. 2012;21(3-4):388-97. 